Revista Destaques Acadêmicos, Lajeado, v. 13, n. 2, 2021. ISSN 2176-3070

DOI: http://dx.doi.org/10.22410/issn.2176-3070.v13i2a2021.2917

http://www.univates.br/revistas

\title{
A PERFORMANCE DA PEQUENA PROPRIEDADE RURAL NO INTERIOR DO RIO GRANDE DO SUL
}

\author{
Fernanda Turra ${ }^{1}$, Leandro Lumbieri ${ }^{2}$, Tania $\mathrm{Craco}^{3}$, \\ Uiliam Hahn Biegelmeyer ${ }^{4}$, Maria Emilia Camargo ${ }^{5}$
}

\begin{abstract}
Resumo: O agronegócio é um dos principais setores da economia nacional e dentro dele destaca-se a agricultura familiar. Em vista disso, optou-se por fazer um estudo de caso em uma propriedade agrícola familiar. $\mathrm{O}$ objetivo desse estudo foi identificar se a pequena propriedade rural foi rentável quando comparada com outros investimentos oferecidos pelo mercado financeiro nesse período. Para poder atingir este objetivo, utilizou-se conceitos de contabilidade e sua aplicabilidade na agricultura familiar e o agronegócio no Brasil e as opções de investimento oferecidas pelo mercado financeiro. Foi utilizada como unidade de pesquisa, uma pequena propriedade rural. Os principais resultados encontrados foram que a propriedade é rentável quando comparada com todas as demais opções do mercado financeiro pesquisadas no período da amostra; e um índice de capital de terceiros sobre o ativo total que sugere baixo problema de liquidez.
\end{abstract}

Palavras-chave: Agricultura familiar; Rentabilidade; Indicadores financeiros.

\section{INTRODUÇÃO}

No cenário econômico brasileiro atual, o agronegócio destaca-se na criação de emprego, gerando um bom resultado na balança comercial (DE CESARO, 2007). Dentro do agronegócio, segundo Thomaz, Kronbauer, Alberton (2014), destaca-se a agricultura familiar, que é responsável por grande parte da produção dos alimentos consumidos no Brasil, tornando-se também, a principal renda para a sustentabilidade das pequenas cidades.

1 Bacharel em Processos Gerenciais.

2 Mestre em Ciências Contábeis.

3 Doutora em Administração.

4 Doutor em Administração.

5 Doutora em Engenharia de Produção 
Segundo informações da Embrapa (2015), atualmente, a agricultura familiar engloba 4,3 milhões de unidades produtivas, o que corresponde a $84 \%$ do total. Também ocupa 14 milhões de pessoas que representam, em média, $74 \%$ do total das ocupações distribuídas e 80.250 .453 hectares ( $25 \%$ da área total). A produção resultante da agricultura familiar destina-se basicamente para as populações urbanas, locais. A mesma, também é essencial para a segurança alimentar. Quanto ao retorno financeiro da agricultura familiar, a página do Portal Brasil - I (2015) menciona que a renda dos produtores familiares cresceu $52 \%$ nos últimos 10 anos.

Na visão de Barbosa et al. (2012), os produtores rurais precisam planejar sobre o negócio, controlar os gastos, conhecer o lucro gerado e tomar decisões estratégicas. E com isso, identificar o seu desempenho financeiro e conhecer a viabilidade do seu negócio. Dentre os produtores rurais, Lourenzani (2005, p. 44) menciona que "no meio rural, os agricultores familiares são os que geram mais emprego e fortalecem o desenvolvimento local, pois distribuem melhor a renda e são responsáveis por parte significativa da produção (...)". "Uma agricultura familiar forte e rentável pode contribuir para a redução da fome, do desemprego rural, do êxodo rural e para o crescimento da produção de alimentos (...)". (SALDANHA, 2005, p. 28)

Além disso, Caetano (2015) destaca que a pecuária leiteira é desenvolvida em aproximadamente $40 \%$ das propriedades rurais do Brasil, sendo explorada, principalmente por pequenos e médios produtores. Ela é importante, pois fixa o homem no campo, reduz as pressões sociais nas áreas urbanas e contribui para a minimização do desemprego e da exclusão social. Além disso, toda a movimentação dos recursos envolvidos na cadeia produtiva do leite contribui para o desenvolvimento da região, onde a mesma está inserida. (MILINSKI; GUEDINE; VENTURA, 2008).

Para Oliveira (2012), a análise econômica da atividade leiteira é importante para o produtor, pois assim ele passa a conhecer e utilizar de maneira econômica e inteligente os fatores de produção. Segundo Alencar et al. (2001), as relações que se estabelecem no setor agropecuário são de concorrência imperfeita, pois as empresas atuantes são reduzidas e organizadas em associações de interesse, que interagem com um grupo de produtores rurais. Essa situação faz com que os produtores percam o poder de negociação do seu produto. Logo, surge a importância de saber se suas negociações estão sendo rentáveis.

Com base no exposto, surge o problema da presente pesquisa: Se esta pequena propriedade rural do município de Novo Machado foi rentável quando comparado com outros investimentos oferecidos pelo mercado financeiro no ano 2014 ?

Em consonância a isso o objetivo geral é identificar se a pequena propriedade rural do município de Novo Machado foi rentável quando 
comparada com outros investimentos oferecidos pelo mercado financeiro no ano 2014.

\section{REFERENCIAL TEÓRICO}

\section{Agronegócios}

O agronegócio é um setor que engloba a produção, processamento, armazenamento e distribuição dos produtos agrícolas, além de acrescentar os aspectos agropecuários. No Brasil, é uma atividade próspera, segura e rentável, pois o país possui um clima diversificado, chuvas regulares, energia solar abundante e quase $13 \%$ da água doce do planeta. No decorrer dos anos, o setor obteve um crescimento sustentável tornando-se um dos mais importantes do Brasil. Isso foi possível, pois o Governo adotou uma série de reformas políticas para o desenvolvimento desse setor (DA SILVA; CESÁRIO; CAVALCANTI, 2010).

Segundo Carlos (2008) o agronegócio no Brasil teve início com o processo de ocupação do território nacional, além dos vários ciclos agroindustriais como a cana-de-açúcar, a borracha, o café, e recentemente, a soja. Entre as décadas de 1970 a 1990, com o desenvolvimento da tecnologia, foi possível dominar regiões que ofereciam poucas oportunidades ao homem, fazendo surgir a oferta de muitos produtos.

Entre janeiro a agosto de 2014, as exportações do agronegócio brasileiro alcançaram U\$\$ 67,61 bilhões, com destaque a soja. Já no período de setembro de 2013 a agosto 2014, o agronegócio brasileiro exportou um montante de U\$\$ 98,54 bilhões (MINISTÉRIO DA AGRICULTURA E PECUÁRIA - B, 2015). Igualmente, em agosto de 2014, o estado do Rio Grande do Sul estava entre os três estados com maior índice de participação nos valores arrecadados nas exportações do agronegócio no país (US\$ 3,66 bilhões), com destaque à soja com e a carne bovina. (MINISTÉRIO DA AGRICULTURA E PECUÁRIA - A, 2015).

Guilhoto et al. (2006) afirmam também que os grandes números de unidades de produção rural divergem em termos de tamanho, capital e tecnologia, tornando as propriedades individuais diferentes. No caso das propriedades de menor porte, o problema é acentuado, devido a diversidade de sistemas e estratégias produtivas. Associações e cooperativas facilitam a permanência do sistema familiar em algumas regiões. Cabe ao governo e as comunidades a promoção de medidas capazes de alterar os rumos da produção familiar.

Através do Censo agropecuário de 2006, foram identificados 4.367 .902 estabelecimentos da agricultura família, o que representava, na época, $84,4 \%$ dos estabelecimentos brasileiros, com uma média de 18,37 hectares por estabelecimento (IBGE, 2015). Se fizermos um comparativo com o ano de 2014, 
no Brasil, o setor da agricultura familiar continua englobando 4,3 milhões de unidades produtivas, o que representa um total de $84 \%$ de todo o território nacional. Além disso, aproximadamente 14 milhões de pessoas estão ocupadas (74\% do total das ocupações), distribuídas em 80.250.453 hectares, o que corresponde a $25 \%$ da área total do Brasil. (EMBRAPA, 2015).

Em vista dos dados apresentados e sabendo-se da importância da agricultura familiar hoje no Brasil, muitos estudos já foram feitos sobre esse assunto. Em pesquisa, percebeu-se que a mesma passou a ser objeto de estudo até mesmo para a área contábil, onde acompanhamentos, que até então eram vistos somente na gestão de empresas, estão sendo aplicados no setor agrícola. Porém, como já mencionado anteriormente, muito desses acompanhamentos são apenas para fins fiscais ou estudo científico.

\section{Contabilidade e finanças no agronegócio}

Desde a antiguidade, o homem tem realizado esforços no sentido de organizar e gerenciar seus lucros, objetivando a maximização de suas riquezas. A contabilidade tornou isso possível, pois no decorrer de sua evolução histórica, ela se configurou como uma das principais responsáveis pela gestão das empresas. Seja na indústria, no comércio, ou até mesmo no campo, ela é responsável por informar aos empresários a situação de seu negócio. Contudo, no campo, ela vem ganhando espaço e importância, apesar de seu uso ser tardio e lento, além de enfrentar resistência. (ULRICH, 2009).

No Brasil, segundo Ulrich (2009), nas últimas décadas, o produtor rural tem apresentado um crescente e acelerado processo de conhecimento sobre conceitos e técnicas contábeis e de gestão do agronegócio. Assim, a administração da propriedade rural ganha qualidade e autonomia na gerencia de suas atividades. Para Crepaldi (2004), a contabilidade rural é uma necessidade urgente no Brasil, porém pouco utilizada, tanto pelos empresários como contadores. Ela controla o patrimônio das entidades rurais, apura o resultado das mesmas e presta informações sobre o patrimônio e o resultado aos diversos usuários.

Crepaldi (2004) afirma ainda que a contabilidade rural controla o patrimônio das propriedades rurais, apura o resultado das mesmas além de prestar informações sobre o resultado obtido aos diversos usuários da contabilidade. Também mede o desempenho financeiro da propriedade e de cada atividade produtiva; apoia a tomada de decisão; permite a comparação do desempenho junto a outras entidades entre outros.

Ela é a radiografia de uma empresa rural, e deve ser acompanhada de perto pelo seu proprietário. (ULRICH, 2009). Sua finalidade é orientar o proprietário nas operações agrícolas e pecuárias, medir e controlar o desempenho econômico e financeiro das empresas e da atividade produtiva, apoiar as tomadas de decisões no planejamento da produção, das vendas e 
investimentos, auxiliar nas projeções de fluxos de caixas, permitir comparações ao desempenho da empresa com outras, conduzir as despesas pessoais do proprietário e de sua família, justificar a liquidez e a capacidade de pagamento junto aos credores, servir de base para seguros, arrendamentos e outros contratos e gerar informações para a Declaração do Imposto de Renda (CREPALDI, 2004).

Quanto ao desempenho de uma atividade agropecuária, Lourenzani (2005) menciona que a mesma está condicionada a diversos fatores da cadeia produtiva, como fornecedores de insumos, processadores, atacadistas e varejistas. Existem ainda instituições e organizações que oferecem suporte financeiro, tecnológico, legal e de informações e políticas macroeconômicas que afetam a rentabilidade da agricultura familiar e de sua sustentabilidade, de forma direta ou indireta. Dessa forma, os proprietários que conseguem inserir seus produtos no mercado, sejam por meio de cooperativas, agroindústrias, entre outros, tem mais chance de obter sucesso em seu negócio.

Na tentativa de melhorar os resultados financeiros, Saldanha (2005), apresenta algumas medidas que o pequeno proprietário rural pode utilizar como: controle contábil, planejamento de curto e longo prazo, cotação de preços na compra de insumos e na venda de seus produtos. Com ajuda dessas medidas e profissionais da área contábil, o proprietário planeja suas finanças e decide a forma de gerir sua propriedade. Identifica receitas e despesa, analisando e interpretando-as para facilitar na escolha das alternativas de produção mais viáveis. (SELLA; ICHIKAWA; LOPES, 2008).

As decisões tomadas em uma propriedade rural, segundo Saldanha, 2005, são determinadas não apenas por fatores como lucro, mas também pela necessidade da família. Afirma que a propriedade rural visa acima da rentabilidade à estabilidade da família, pois é a forma de sustento e coesão doméstica. Assim, o proprietário precisa de modelos que o ajudem a direcionar suas análises, em especial à financeira, uma vez que o agricultor acumula várias funções, e muitas vezes tomam decisões sem preparo, ou por meio de tentativas ou erros.

\section{Indicadores econômico-financeiros}

Para avaliar o desempenho de determinada atividade econômica, existem alguns índices que a contabilidade aplica ao Balanço Patrimonial e ao Demonstrativo de Resultado do Exercício, através de fórmulas que darão origem a determinados dados. Para Gitman (2010), a análise de índices envolve métodos de cálculos e interpretação de índices financeiros para analisar e monitorar o desempenho da empresa.

Gitman (2010) apresenta cinco categorias diferentes para calcular os índices financeiros, são eles: liquidez, atividade, endividamento, lucratividade e valor de mercado. Os índices de liquidez, lucratividade e endividamento 
medem riscos, o índice de valor de mercado mede tanto riscos como retorno e os índices de lucratividade medem retornos. Abaixo, são apresentados os índices de endividamento, sendo que os índices de rentabilidade serão apresentados em um capítulo específico para estes.

- Índices de endividamento: o cálculo desses índices indica quanto dinheiro de terceiros a empresa usa para gerar seus lucros. (GITMAN, 2010). "Quanto mais dívidas uma empresa usa em relação a seu ativo total, maior a sua alavancagem financeira". (GITMAN, 2010, p. 55). Iudícibus (2010) apresenta três indicadores de endividamento: quociente de participação de capital de terceiros sobre os recursos totais, quociente de capitais de terceiros/capitais próprios e quociente de participação das atividades de curto prazo sobre o endividamento. Para Gitman (2010) os índices de endividamento são calculados através do índice de endividamento geral, índice de cobertura de juros e índice de cobertura de obrigações fixas.

- Indicadores de rentabilidade: De modo geral, o estudo da rentabilidade de um investimento relaciona o lucro obtido com algum valor que expresse a dimensão relativa do mesmo, para depois analisar o resultado obtido em determinado período. Para o cálculo dos resultados obtidos, é importante que o conceito usado no numerador seja compatível com o conceito usado no denominador. (IUDÍCIBUS, 2010). Segundo Gitman (2010), os índices de rentabilidade permitem avaliar os lucros da empresa em relação a um dado nível de vendas, de ativos ou investimentos. É necessário gerar lucro para que uma empresa possa atrair capital externo. Ele apresenta seis índices para o cálculo de rentabilidade: margem de lucro líquido, margem de lucro operacional, margem de lucro líquido, lucro por ação, retorno sobre o ativo total e retorno sobre capital próprio. Segue abaixo os principais índices de rentabilidade.

- Margem de lucro bruto: "mede a porcentagem de cada unidade monetária de venda que permanece após a empresa deduzir o valor dos bens vendidos". GITMAN (2010, p. 58). Quanto maior a margem, melhor. Já Hoji (2010) diz que este indica quanto lucro bruto a empresa obtém para cada $\mathrm{R} \$ 1,00$ de receita líquida.

- Margem do lucro operacional: mede a porcentagem de cada unidade monetária de vendas remanescentes após a dedução de todos os custos e despesas. Representa o lucro puro, pois mede apenas o lucro sobre as operações e desconsidera impostos e dividendos de ações preferenciais. Quanto mais elevada, melhor (GITMAN, 2010).

- Margem de lucro líquido: esse índice, segundo Gitman (2010), mede a porcentagem de cada unidade monetária de vendas remanescente, após deduzir todos os custos e impostos. Quanto mais elevada, 
melhor. Essa medida é relacionada, frequentemente, ao sucesso da empresa com relação ao lucro obtido através das vendas.

- Retorno sobre o ativo total (ROA): esse índice, para Gitman (2010, p. 60), "mede a eficácia da administração na geração de lucros a partir dos ativos disponíveis". Quanto maior esse retorno, melhor.

- Retorno sobre capital próprio (ROE): segundo Gitman (2010), esse índice mede o retorno sobre os investimentos dos acionistas. Quanto mais alto, melhor.

Para Iudícibus (2010, p. 112), o cálculo sobre o capital próprio, "expressa resultados globais auferidos pela gerência na gestão de recursos próprios e de terceiros, em benefício de acionistas".

\section{METODOLOGIA}

\section{Classificação da pesquisa}

Este trabalho apresentou uma pesquisa documental, pois os dados foram extraídos a partir de documentos já existentes na propriedade, como por exemplo, notas fiscais e Bloco do Produtor Rural, sendo que todos foram obtidos direto da fonte de pesquisa. Além disso, referiu-se a um estudo de caso, pois escolheu-se apenas uma única propriedade para a coleta e análise dos dados: a pequena propriedade do município de Novo Machado. Esta propriedade foi o objeto de estudo para conseguir alcançar o objetivo geral e os objetivos específicos.

\section{Objeto de pesquisa}

A escolha desta propriedade deu-se pelo fato de haver, uma proximidade com os proprietários, o que facilitou o acesso às informações. Esta propriedade possui como atividade principal, a agropecuária leiteira, a qual é comum entre as pequenas propriedades rurais do município. Nesta propriedade é empregada a mão de obra do proprietário, sua esposa e seu filho. A quantidade de vacas em lactação varia de 10 a 15 cabeças, distribuídas em, aproximadamente, dois hectares de pastagens permanentes. Além disso, tem pastagens de inverno e verão e o cultivo de milho para a fabricação de silagem.

Quanto à receita da atividade, a mesma varia conforme a quantidade de leite vendido e o valor que o mercado paga pelo produto. Esse valor depende muito da oferta e procura. Assim, o valor pago pelo produto varia muito dentro de um período anual.

Para a Emater - RS (2015), na região da Grande Santa Rosa, onde se localiza a propriedade que será estudada, predomina a agricultura familiar, que ocupa um total de 198 mil hectares. Predomina nessa região, o cultivo de soja, milho e o gado leiteiro. Ainda segundo a Emater - RS (2015), a produção leiteira 
tem um significativo potencial de crescimento no estado, devido a fatores como o clima temperado, fertilidade do solo, boa disponibilidade de água, produção predominantemente à base de pasto, em propriedades familiares e com baixo custo de produção.

Nessa propriedade, predomina a agricultura familiar com destaque à agropecuária leiteira, além do cultivo de soja, (destinado à venda do grão) e milho (para o processamento de silagem que é destinada à alimentação do gado). Essas atividades são exercidas em uma área de aproximadamente 18 hectares de terra (seis hectares em nome do dono e o restante são arrendados). Desses, dois hectares são pastagens permanentes (potreiro), um hectare de mata nativa e a outra parte é destinada ao plantio de soja, milho, pastagens de inverno e verão.

A atividade leiteira consiste na principal fonte de renda dessa família, com uma média de 10 a 15 vacas em produção constante. A média mensal de produção é de 3.000 a 5.000 litros de leite, variando conforme o clima, a quantidade de vacas em produção e a quantidade de pasto. A soja é uma renda complementar, tendo uma média de 300 sacos/ano. Já o milho, é feito o plantio em duas etapas, ambas usadas no processamento de silagem.

No ano estudado, a propriedade obteve um faturamento médio mensal de $R \$ 6.500,00$ entre a venda de leite e soja. Contudo, não se tem conhecimento se esse retorno cobre as despesas, se a atividade apresenta uma lucratividade ou ainda se está sendo rentável.

O proprietário avalia a propriedade em, no mínimo, $\mathrm{R} \$ 200.000,00$. Este valor, por sua vez, poderia ser investido de outra forma, como por exemplo, os investimentos ofertados pelo mercado financeiro, como poupança, dólar, ouro, CDB e ações na Bovespa. Estes investimentos têm apresentado retornos positivos, como podemos observar no dólar que iniciou 2014 a $\mathrm{R} \$ 2,39$ $(01 / 01 / 2014)$ e fechou o ano a $\mathrm{R} \$ 2,66(31 / 12 / 14)$. Já a poupança, teve um rendimento acumulado no ano de 2014 de 7,07\%. (PORTAL BRASIL - A, B e C, 2014).

\section{Plano de coleta e tratamento dos dados}

Para que os objetivos propostos fossem alcançados, coletou-se os dados necessários junto à propriedade através de entrevistas com o proprietário e em documentos já existentes. Esses dados foram encontrados principalmente em notas fiscais de entrada e saída e no Bloco do Produtor Rural. Quanto aos valores de maquinários necessários para a realização das tarefas, valores das terras e dos estabelecimentos, os mesmos foram avaliados pelo próprio proprietário, tendo como base preço médio de mercado local.

Com os documentos em mãos, elaborou-se o Demonstrativo de Resultado do Exercício (DRE) da propriedade, apresentando informações importantes como valor da receita, despesas, custo da atividade e o resultado 
(lucro ou prejuízo), dentro do período analisado. Além deste, criou-se o Balanço Patrimonial, informando dados sobre valores do ativo, passivo, bens, direitos e Patrimônio Líquido (PL). Após a elaboração destes, calculou-se os indicadores de rentabilidade: Retorno Sobre o Capital Próprio (ROE) e Retorno Sobre o Ativo Total (ROA).

Também coletou-se via internet, o percentual de rendimento dos indicadores de desempenho econômico do mercado financeiro ofertados em 2014, conforme citados anteriormente. Após, fez-se a comparação desses resultados com os apresentados pela propriedade. Logo abaixo segue um resumo das opções de investimento do mercado econômico para maior conhecimento sobre as mesmas.

A última etapa foi comparar os indicadores obtidos pela propriedade com os valores encontrados nas opções de investimento do mercado financeiro. Após essas comparações, verificou-se qual dos investimentos foi mais rentável. Apresentou-se os dados obtidos aos proprietários, para que os mesmos fizessem suas observações a respeito do desempenho apresentado pela propriedade no decorrer de 2014.

\section{LIMITAÇÕES DO MÉTODO}

Através da atividade proposta, encontrou-se alguns pontos na forma de avaliação das informações coletadas que devem ser levadas em consideração, pois as mesmas limitaram o resultado da pesquisa. As principais observações são:

- estudou-se a rentabilidade apenas no período de 2014. Os resultados anteriores foram ignorados e estes, por sua vez, poderiam indicar uma perspectiva de comportamento, positiva, o que sugeriria a continuidade do investimento, ou negativa, sugerindo o contrário;

- os valores da terra, cabeças de gado, implementos agrícolas, instalações entre outros, foram estipulados pelo próprio proprietário com base no valor do mercado regional;

- o valor do Patrimônio Líquido também foi estimado, uma vez que não havia valor formal, feito por um profissional da área contábil que acompanhe a propriedade;

- pelo fato de não haver um controle administrativo da propriedade, estipulou-se, ainda, valores de pró-labore e algumas despesas que não estavam disponíveis em notas fiscais.

\section{ANÁLISE E DISCUSSÃO DOS RESULTADOS}

Conforme mencionado no plano de coleta de dados, separou-se e classificou-se as notas fiscais para posteriormente, montar o Balanço Patrimonial e o Demonstrativo de Resultado do Exercício (DRE). Também pesquisaram- 
se os índices de desempenho dos investimentos econômicos oferecidos pelo mercado financeiro.

Primeiramente, separaram-se as notas fiscais guardadas pelo proprietário no período de 2014; após fez-se cópias daquelas que o proprietário não podia se desfazer como notas de defensivos, adubos e sementes que são necessárias para o custeio da safra. Quanto às demais, utilizou-se as originais. Como terceiro passo, classificaram-se as notas para a construção do DRE, lançado os valores numa planilha do Excel para apuração dos dados.

Conversou-se com o proprietário para coletar informações que estavam subentendidas nas notas, como apuração de impostos, despesas e custos com o plantio e colheita (quando paga-se um terceiro para efetuar os mesmos). A apuração dessas informações é importante, para que o resultado final da pesquisa esteja o mais próximo possível à realidade vivida pelo proprietário.

Com esses dados em mãos, montou-se o DRE. Iniciou-se sua montagem a partir da receita operacional líquida, pois os valores dos impostos são abatidos já na emissão das notas fiscais e as mesmas são com o valor líquido da venda. Por exemplo: simulamos uma venda de $\mathrm{R} \$ 100,00$ onde são descontados 2,3\% de FUNRURAL (imposto que o produtor paga pelo produto vendido). Assim, o valor da nota será de $\mathrm{R} \$ 97,70$.

Estipularam-se os valores de água e energia. A água que o gado bebe vem de um poço, açudes e sangas encontrados na propriedade. Utiliza-se a água potável apenas em períodos de estiagem e para a lavagem dos equipamentos de ordenha das vacas. Já a luz, calculou-se uma média de $30 \%$ do total que seria destinada a ordenha e resfriamento do leite. Outro fato importante que deve ser ressaltado, é que a energia elétrica na zona rural é mais barata quando comparado com o valor pago na zona urbana.

Outros impostos que são pagos pelo proprietário são os destinados ao produtor rural, como o Imposto Territorial Rural (ITR) e o INCRA. Esses, normalmente são pagos em intervalos maiores de um ano. Assim, dividiu-se o valor total pago pela quantidade de períodos para chegar-se ao valor anual. Abaixo seguem os dados obtidos no DRE. 
Quadro 1. Demonstrativo de Resultado do Exercício da Propriedade Rural em 2014

\section{DEMONSTRATIVO DE RESULTADO DA PEQUENA PROPRIEDADE DE NOVO MACHADO}

RECEITA OPERACIONAL LÍQUIDA: R\$ 87.107,59

(-) CUSTO DO PRODUTO VENDIDO: R\$ 19.435,79

CPV: R\$ $18.135,79$

Mão de obra: $R \$ 500,00$

Água: R\$ 200,00

Energia Elétrica: R\$600,00

= RESULTADO OPERACIONAL BRUTO: R\$ 67.671,80

(+/-) RECEITAS/DESPESAS OPERACIONAIS: R\$ 28.567,79

(-) DESPESAS ADMINISTRATIVAS: R\$ 28.633,01

Pró-labore: $\mathrm{R} \$ 18.000$

Arrendamento da terra: $R \$ 1.250,00$

Despesas Produtivas: R\$3.916,01

Manutenção de equipamentos: R\$ $5.000,00$

Seguros: R\$ 432,00|

ITR: R $\$ 15,00$

INCRA: R\$ 20,00

(-) DESPESAS COMERCIAIS/VENDA: 0,00

(-) DESPESAS FINANCEIRAS: R\$ 0,00

(+) RECEITAS FINANCEIRAS: R\$ 65,22

Descontos recebidos: R\$ 65,22

(+/-) OUTRAS RECEITAS/DESPESAS OPERACIONAIS: R\$ 1.500,00

(-) OUTRAS DESPESAS: R\$ 2.000,00

Despesas diversas: $2.000,00$

(+) OUTRAS RECEITAS: R\$ 500,00

Vendas diversas: $R \$ 500,00$

= RESULTADO OPERACIONAL LÍQUIDO: R\$ 37.604,01

= RESULTADO ANTES DO IR/CSSL: RS 37.604,01

= LUCRO OU PREJUÍZO DO EXERCÍCIO: R\$ 37.604,01

Fonte: Elaborado pelos autores.

Quanto à elaboração do Balanço Patrimonial, não foi possível montálo com sua estrutura formal, pois na propriedade não existem registros que possibilitem a criação do mesmo nesse formato. Contudo, buscou-se o máximo de informações possíveis para sua elaboração.

Os valores dos bens foram impostos pelo próprio proprietário, com base no mercado da região. Foram computadas as vacas em lactação e as novilhas. $\mathrm{O}$ valor dos fornecedores originou-se da coleta de dados das notas fiscais. Coletou-se também a quantidade $(\mathrm{R} \$$ ) de financiamentos e empréstimos feitos no período. Quanto ao valor do pró-labore, estabeleceu-se uma média de gastos que o proprietário tem para manter as necessidades básicas dos componentes 
da família que contribuem para o desempenho da atividade. Abaixo, segue os resultados obtidos com a criação do Balanço Patrimonial.

Quadro 2. Balanço Patrimonial da Propriedade Rural

\begin{tabular}{|c|c|c|c|c|c|}
\hline \multicolumn{6}{|c|}{ BALANÇO PATRIMONIAL DA PROPRIEDADE RURAL 12/2014 } \\
\hline ATIVO & $\mathbf{R S ̧}$ & $204.000,00$ & PASSIVO & $\mathbf{R S ̧}$ & $51.581,82$ \\
\hline BENS & $\mathbf{R S}$ & $204.000,00$ & Obrigações & $\mathrm{R} \$$ & $51.581,82$ \\
\hline Caixa e Equivalentes de Caixa & $\mathrm{R} \$$ & - & Fornecedores: & $\mathrm{R} \$$ & $23.581,82$ \\
\hline Reforma de maquinários & $\mathrm{R} \$$ & $2.000,00$ & Financiamento (custeio) & $\mathrm{R} \$$ & $10.000,00$ \\
\hline Recuperação do solo & $\mathrm{R} \$$ & $5.000,00$ & Pró-labore a pagar: & $\mathrm{R} \$$ & $18.000,00$ \\
\hline Terreno & $\mathrm{R} \$$ & $122.000,00$ & & & \\
\hline Veículos & $\mathrm{R} \$$ & $3.000,00$ & & & \\
\hline Trator & $\mathrm{R} \$$ & $16.000,00$ & PATRIMONIO LÍQUIDO: & $\mathrm{RS}$ & $152.418,18$ \\
\hline Galpão e sala de ordenha & $\mathrm{R} \$$ & $16.000,00$ & Capital Social: & $\mathrm{R} \$$ & $114.814,17$ \\
\hline Cabeças de gado & $\mathrm{R} \$$ & $40.000,00$ & Lucro/prejuízo do exercício: & $\mathrm{R} \$$ & $37.604,01$ \\
\hline DIREITOS & $\mathbf{R S S}$ & - & & & \\
\hline Ativo Total & $\mathbf{R S S}$ & $204.000,00$ & Passivo + PL & & $204.000,00$ \\
\hline
\end{tabular}

Fonte: Elaborado pelos autores.

Após a montagem do DRE e do Balanço Patrimonial, calculou-se os indicadores de Rentabilidade (ROE e ROA). Também coletou-se os indicadores de desempenho das opções de investimento do mercado, tendo como base os dados do Banco Central do Brasil e Instituto Assaf. Posteriormente, montou-se o quadro comparativo dos resultados, conforme ilustrado abaixo:

Quadro 3. Quadro comparativo de valores

\begin{tabular}{|} 
COMPARATIVO DE INDICADORES ECONÔMICOS E DA PROPRIEDADE \\
\begin{tabular}{|c|c|}
\hline INVESTIMENTO & $\begin{array}{c}\text { RENDIMENTOS } \\
\mathbf{2 0 1 4}(\%)\end{array}$ \\
\hline OURO & 12,04 \\
\hline CDB & 10,07 \\
\hline POUPANÇA & 7,08 \\
\hline IBOVESPA & $-2,91$ \\
\hline DÓLAR & 13,39 \\
\hline ROE & 32,75 \\
\hline ROA & 18,43 \\
\hline
\end{tabular}
\end{tabular}

Fonte: Elaborado pelos autores. 
Após a análise dos dados obtidos, tanto da propriedade como das opções de investimento do mercado, pode-se concluir que:

a) quando comparada com o ouro, a propriedade apresentou um rendimento de 20,71 pontos percentuais (pp) a mais, calculando o indicador ROE. Já o ROA, apresentou uma rentabilidade de 6,39 pp a mais;

b) quando comparada com o CDB, o resultado do indicador de rentabilidade foi de 22,68 pp a mais. Já o indicador ROA, apresentou um índice de 8,36 pp a mais;

c) quando comparada com um investimento na poupança, a diferença entre os valores obtidos são ainda maiores. O ROE apresentou um rendimento de 25,67 a mais e o ROA 11,35 pp a mais;

d) quando comparada com o índice da Ibovespa, a propriedade apresentou resultados ainda mais positivos, uma vez que o mesmo teve índice negativo no período estudado;

e) quando comparada com o dólar, a propriedade teve um rendimento de 19,36 pp a mais se calculado e ROE e 5,04 pp a mais se calculado o ROA.

Com a coleta de dados e demais informações levantadas durante o estudo, montou-se um gráfico para melhor representar ou comparar os resultados obtidos. Logo abaixo segue o esboço do mesmo, enfatizando os rendimentos obtidos pela propriedade.

Gráfico 1. Comparativos dos indicadores da propriedade e do mercado

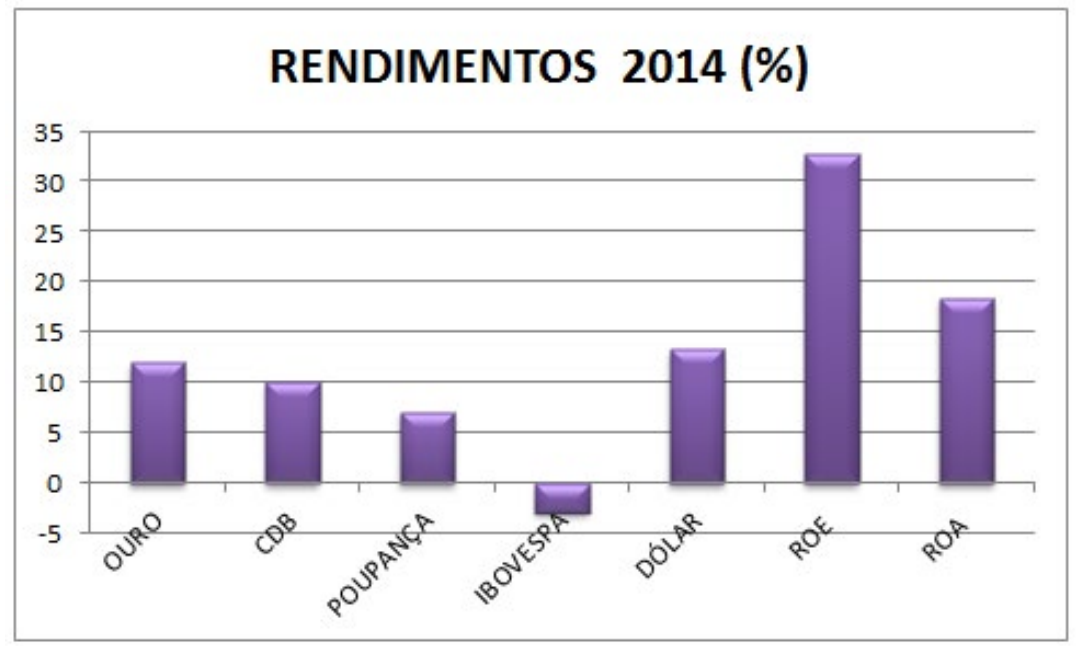

Fonte: Elaborado pelos autores. 
A fim de aprofundar ainda mais a pesquisa, optou-se por calcular o índice de endividamento da propriedade. Para o cálculo do mesmo, usou-se como base os conceitos de Iudícibus (2010), conforme mencionado no referencial teórico. Abaixo segue o Quadro 4 com o resultado encontrado.

Quadro 4. Cálculo do índice de endividamento

\begin{tabular}{|c|c|c|}
\hline ÍNDICE DE ENDIVIDAMENTO & VALORES & RESULTADO \\
\hline $\begin{array}{c}\text { Quociente de Participação de Capitais de } \\
\text { Terceiros sobre os Recursos Totais: } \\
\frac{\text { Exegível total }}{\text { Exegível total + patrimônio líquido }}\end{array}$ & $\frac{51.581,82}{51.581,82+152.418,18}$ & $25,28 \%$ \\
\hline
\end{tabular}

Fonte: Elaborado pelos autores.

Após o cálculo do indicador, teve-se um índice de endividamento de $25,28 \%$. Segundo Iudícibus (2010), este representa a relação entre capital próprio e capital de terceiros. Logo, dos recursos totais aplicados na propriedade para a execução das atividades, aproximadamente $25 \%$ são recursos de terceiros e $75 \%$ são recursos próprios.

Percebe-se assim que, por mais que o mercado financeiro apresente formas de investir o capital, e que podem dar bons retornos, para o proprietário não seria viável desfazer-se da propriedade e investir seu valor em uma das opções propostas. Os retornos obtidos não iriam suprir as necessidades da família.

\section{CONSIDERAÇÕES FINAIS}

Como visto anteriormente, o agronegócio é um dos principais setores da economia nacional, com grande participação nas exportações e no resultado do PIB. Dentro do agronegócio destaca-se a agricultura familiar. Ela é importante, pois fixa o homem no campo, contribui para a segurança alimentar, diminui o desemprego entre outros fatores.

Dentro deste cenário, surgiu a oportunidade de fazer um estudo em uma pequena propriedade rural no município de Novo Machado, interior do Rio Grande do Sul, onde predomina a agricultura familiar. O problema da pesquisa foi identificar se esta pequena propriedade foi rentável no ano de 2014 quando comparada com outros investimentos oferecidos pelo mercado financeiro nesse período.

A área contábil tem como um dos objetivos auxiliar na administração das empresas, informando ao empresário a situação do negócio. No setor agrícola, em especial, na agricultura familiar, não é muito comum a utilização de registros contábeis, visto as dificuldades dos pequenos agricultores. Como 
já mencionado, os registros contábeis no setor agrícola são importantes, pois os produtores rurais precisam planejar o negócio, controlar os gastos, conhecer o lucro gerado e tomar decisões estratégicas (BARBOSA et al., 2012).

Para responder o problema de pesquisa, fez-se necessário mensurar os dados contábeis e financeiros da propriedade no ano de 2014. Também foram calculados os indicadores de rentabilidade da propriedade e coletados os indicadores de desempenho das opções de investimento ofertadas pelo mercado financeiro em 2014. Por último, foram construídos quadros e gráficos com os indicadores obtidos da propriedade e os indicadores de desempenho das opções de investimento do mercado desse período.

Chegou-se aos dados necessários para desenvolver o trabalho. A propriedade apresentou, em 2014, um lucro de $\mathrm{R} \$ 37.604,01$; um patrimônio líquido de $\mathrm{R} \$ 152.418,18$; um retorno sobre o capital próprio de $32,75 \%$; um retorno sobre o ativo total de $18,43 \%$. Além disso, quando calculado o índice de participação do capital de terceiros sobre os recursos totais, apresentou-se um índice de $25,28 \%$.

Estes percentuais de rentabilidade, quando comparados com a rentabilidade de outros investimentos ofertados pelo mercado, mostraramse superiores em comparação com todas as demais opções observadas. Com base nesta comparação, pode-se observar que para o período pesquisado, a propriedade foi mais rentável, não sendo viável ao proprietário desfazer-se dela, como havia sido questionado (ou sugerido) anteriormente.

Quando apresentado ao proprietário o resultado do estudo, o mesmo disse que acreditava que a atividade praticada pagava as despesas necessárias para manter a propriedade, bem como as necessidades da família. Contudo, não imaginava que a propriedade fosse apresentar o lucro que apresentou. Disse ainda que esses números não são percebidos no dia a dia, pois o dinheiro gira constantemente e é o lucro da atividade leiteira e do plantio de soja que paga todas as demais despesas.

Esse estudo trouxe muitas informações importantes que o dono do negócio poderá utilizar na administração do mesmo, reforçando a importância de se fazer um acompanhamento do empreendimento, inclusive nesse setor tão importante para o nosso país. Pode-se também utilizar o trabalho como um exemplo que comprova o baixo custo da atividade leiteira no nosso estado e a importância que esse setor do agronegócio tem para a agricultura familiar em nosso país.

Contudo, como já mencionado, algumas limitações encontradas podem ter influenciado no resultado final da pesquisa. Pode-se destacar: a dificuldade no levantamento das informações para montar o DRE e o Balanço Patrimonial; a estipulação de valores das despesas e dos bens; a falta de um controle administrativo; o fato de coletar os dados apenas do período de 2014 e analisar apenas as duas principais atividades econômicas da propriedade. 
Como sugestão para as próximas pesquisas nesse setor da economia, sugere-se fazer um estudo que envolva períodos de tempo maiores bem como incluir todas as atividades que englobam a receita financeira do empreendimento. Pode-se ainda, buscar maiores informações para conseguir montar um balanço patrimonial e um DRE com suas fórmulas estruturais, usualmente conhecidas.

\section{REFERÊNCIAS}

ALENCAR, Edgard et al. Complexos agroindustriais, cooperativas e gestão. Revista organizações rurais e agroindustriais, v. 3, n. 2, 2001.

BARBOSA, Letícia Peter et al. Contabilidade, Gestão de Custos e Resultados no Agronegócio: Um estudo de caso no Rio Grande do Sul. XIX Congresso Brasileiro de Custos - Bento Gonçalves, RS, Brasil, 12 a 14 de novembro de 2012.

CAETANO, Raphael Perini et al. Avaliação do manejo nutricional do rebanho leiteiro nos assentamentos rurais do município de Ilha Solteira - SP. $8^{\circ}$ Congresso de extensão universitária da UNESP, 2015.

CARLOS, Joaquim. A evolução do agronegócio brasileiro no cenário atual.

Revista on line administradores.com, 05 ag. 2008. Disponível em: http:/ /www. administradores.com.br/artigos/economia-e-financas/a-evolucao-do-agronegociobrasileiro-no-cenario-atual/24824/ Acesso em 05/05/2015.

CESARO, De Nestor Henrique; SATUR, Roberto Vilmar; LUZA; Ani Cleie. Perfil e panorama do agronegócio exportador brasileiro em especial da região de Frederico Westphalen. Revista de administradores, v. 6, n.11, p. 11-38, dez 2007.

CREPALDI, Silvio Aparecido. Auditoria contábil: Teoria e prática. São Paulo, Atlas, 2004.

EMATER - RS: http://www.emater.tche.br/site/regionais/santa-rosa.php acesso em $17 / 05 / 15$.

EMBRAPA. https://www.embrapa.br/embrapa-no-ano-internacional-da-agriculturafamiliar Acesso em 03/04/15.

HOJI, Masakazu. Administração financeira e orçamentária: matemática financeira aplicada, estratégias financeiras, orçamento empresarial. $9^{a}$ ed. São Paulo, Atlas, 2010.

GITMAN, Lawrence J. Princípios da administração financeira. Tradução: Allan Vidigal Hastings, Revisão técnica: Jean Jacques Salim, P. 51- 61; 12ª ed., São Paulo, Pearson Prentice Hall, 2010. 
GUILHOTO, Joaquim J. M. et al. A importância do agronegócio familiar no Brasil. Revista de Economia e Sociologia Rural, Rio de Janeiro, vol. 44, nº 03, p. 355-382, jul/ set 2006.

IBGE - Instituto Brasileiro de Geografia e Estatística. http:/ /www.ibge.gov.br/home/ estatistica/economia/agropecuaria/censoagro/ acesso em 10/03/15.

INSTITUTO ASSAF: http:/ / www.institutoassaf.com.br/2012/rendimentos.aspx acesso em 10/07/15.

IUDÍCIBUS, Sérgio de. Análise de balanços. $10^{a}$ ed., $3^{\text {a }}$ reimp, p.92 - 111, São Paulo, Atlas, 2010.

LOURENZANI, Wagner Luiz. Modelo dinâmico para a gestão integrada da agricultura família. Universidade Federal de São Carlos, Tese de doutorado, São Carlos, UFSCar, 2005.

MILINSKI, Claudine Campanhol; GUEDINE, Paulo Sérgio Moreira; VENTURA, Carla Aparecida Arena. $\mathrm{O}$ sistema agroindustrial do leite no Brasil: uma análise sistêmica. $4^{\circ}$ Congresso Brasileiro de Sistemas, Centro Universitário de Franca, Franca, SP, 29 e 30 out 2008 .

MINISTÉRIO DA AGRICULTURA E PECUÁRIA - A: http:/ / www.agricultura.gov. br/comunicacao/noticias/2014/08/sp-mt-e-rs-sao-os-primeiros-no-ranking-doagronegocio. Acesso em 10/05/15.

MINISTÉRIO DA AGRICULTURA E PECUÁRIA - B: http:/ / www.agricultura.gov. br/comunicacao/noticias/2014/09/exportacoes-do-agronegocio-atingiram-uss-67bilhoes-de-janeiro-a-agosto-de-2014. Acesso em 03/04/15.

OLIVEIRA, Alexis Wanderley De. Avaliação de indicadores referência em propriedades leiteiras do estado de Alagoas. Dissertação de mestrado em zootecnia, Universidade Federal de Alagoas, Centro de Ciências Agrárias, Rio Largo, 2012.

PORTAL BRASIL - A: http://portalbrasil.net/2014/economia/dolar_riscopais_ janeiro.htm (2014) Acesso em 10/03/15.

PORTAL BRASIL - B: http:/ / portalbrasil.net/2014/economia/dolar_riscopais_ dezembro.htm (2014). Acesso em 10/03/2015.

PORTAL BRASIL - C: http:/ / portalbrasil.net/poupanca_mensal.htm acesso em 10/03/15.

PORTAL BRASIL - D: http:/ / www.brasil.gov.br/economia-e-emprego/2012/04/ moeda-estrangeira/ acesso em 12/07/15.

PORTAL BRASIL - E: http:/ /www.brasil.gov.br/economia-e-emprego/2012/04/ouro acesso em 10/07/15. 
PORTAL BRASIL - F: http:/ / www.brasil.gov.br/economia-e-emprego/2010/12/ medidas-de-restricao-ao-credito-tornarao-mais-rentaveis-algumas-aplicacoesfinanceiras acesso em 10/07/15.

PORTAL BRASIL - G: http:/ /www.brasil.gov.br/economia-e-emprego/2009/11/bmfbovespa acesso em 10/07/15.

PORTAL BRASIL - H: http:/ /www.brasil.gov.br/economia-e-emprego/2009/11/ remuneracao-da-poupanca-e-atrelada-a-taxa-basica-de-juros acesso em 10/07/15.

SALDANHA, Anaís Naomi Kasuya. Evolução e determinantes da margem bruta em estabelecimentos agropecuários familiares no Norte do Paraná, de 1998 a 2003. Dissertação (Mestrado em Administração), Programa de Pós-Graduação em Administração, Universidade Estadual de Maringá, Maringá, 2005.

SELLA, Flavia Vasconcellos; ICHIKAWA, Elisa Yoshie; LOPES, Paulo. Gestão financeira rural: um estudo no Projeto Redes de Referência para Agricultura Familiar do Paraná. Revista ADMpg Gestão Estratégica, Ponta Grossa v1, n1, p. 91-96, 2008.

SILVA, Maria Gomes Da; CESÁRIO, Andressa Vieira; CAVALCANTI, Ivan Ramos. Relevância do agronegócio para a economia brasileira atual. Centro De Ciências Aplicada/Departamento de Administração/Monitoria, 2010.

ULRICH, Elisane Roseli. Contabilidade rural e perspectivas da gestão no agronegócio. Revista de Administração e Ciências Contábeis do IDEAU, v.4, n.9, 